\title{
Molecular structure of calcium, magnesium, strontium and barium m-nitrobenzoates
}

\author{
Mariola Samsonowicz \\ Department of Chemistry, Bialystok Technical University, Zamenhofa 29, 15-435 Bialystok, Poland \\ Tel.: +480857469795; E-mail: m.samsonowicz@pb.edu.pl
}

\begin{abstract}
The effect of calcium, magnesium, strontium and barium ions on the electronic structure of m-nitrobenzoates was studied. The FT-IR spectra of m-nitrobenzoic acid and its salts were registered, assigned and analyzed. Characteristic shifts and changes in intensities of bands along the metal series were observed. The structures of m-nitrobenzoic acid and its calcium, magnesium, strontium and barium salts were optimized at the B3LYP/LANL2DZ level. Geometric aromaticity indices, atomic charges, dipole moments and energies were also calculated.
\end{abstract}

Keywords: Calcium, magnesium, strontium, barium m-nitrobenzoates, FT-IR, DFT, molecular structure

\section{Introduction}

The metal-carboxylate complexes are used as model systems for the metal-active sites in bioinorganic chemistry to their usefulness as novel materials in materials science. Calcium and magnesium are biologically relevant elements in view of their widespread occurrence in the body and in nature. On the other hand, nitroaromatics are important priority pollutants entering the environment primarily through anthropogenic activities associated with the industrial production of dyes, explosives, pesticides, insecticides and pharmaceuticals. Discharge of these compounds into the environment poses serious health hazards as they are mutagenic and bioaccumulate in the food chain [6]. It seems to be interested to study the alkaline earth metal nitrobenzoates, in which above mentioned properties are connected.

The aim of the works of our team is the investigation of specific effect of various metals on the electronic system and molecular structure of some benzoic acid derivatives $[4,7,8]$. Vibrational spectra and antimicrobial activity of magnesium and calcium benzoates in solid state and water solution were studied by Borawska et al. [1]. Alkali metal m-nitrobenzoates were reported previously [7]. In this paper the effect of alkaline earth elements on the electronic structure of m-nitrobenzoic acid is presented.

\section{Experimental}

Calcium, magnesium, strontium and barium m-nitrobenzoates were prepared by dissolving the powder of m-nitrobenzoic acid in the water solution of the appropriate metal hydroxide in a stoichiometric ratio (2:1). All reagents were obtained from Aldrich Chemical Company. The solution was left at the room temperature for $24 \mathrm{~h}$ until the sample crystallized in the solid state. Precipitants were filtered, washed 


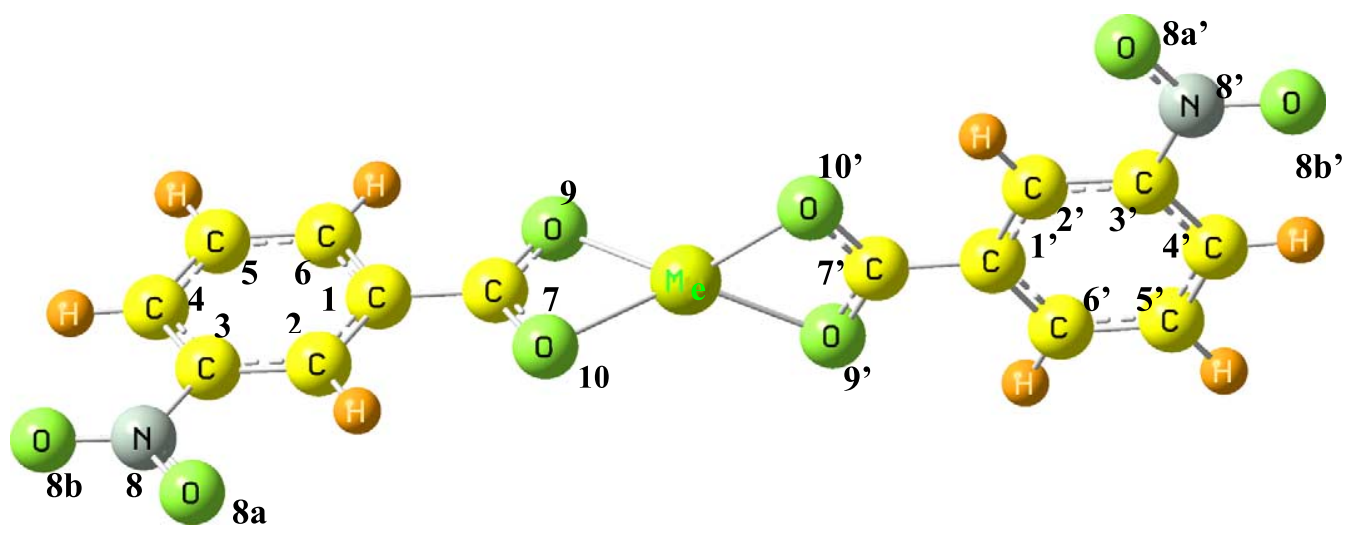

Fig. 1. Atomic number in m-nitrobenzoate molecules.

by water and drying under reduced pressure at $110^{\circ} \mathrm{C}$. Obtained complexes were anhydrous - in the IR spectra of solid state samples the lack of bands characterized for crystallizing water was observed.

The IR spectra were recorded with the EQUINOX 55, BRUKER FT-IR spectrometer within the range $4000-400 \mathrm{~cm}^{-1}$. Samples in the solid state were measured in KBr pellets.

The density functional (DFT) hybrid method B3LYP/LANL2DZ was used to calculate optimized geometrical structures of studied compounds (Fig. 1). All theoretical calculation were performed using the GAUSSIAN 98W (v. 5.4) package [2] of programs running on a PC computer.

\section{Results and discussion}

\subsection{Calculated molecular structure}

The bond lengths, the angles between bonds, geometric aromaticity indices [3] as well as dipole moments, absolute and relative energies for studied compounds were calculated (B3LYP/LANL2DZ) and presented in Table 1. Comparing the bond lengths in aromatic ring one can observe that the values of differences between the bonds decrease in the series $\mathrm{Mg}>\mathrm{Ca}>\mathrm{Sr}>\mathrm{Ba}$ m-nitrobenzoates. The smallest one was noted for barium salt, but the largest for magnesium m-nitrobenzoate. That indicates that the bond lengths are being equalized in above-mentioned series. The values of angles between $\mathrm{C}-\mathrm{C}-\mathrm{C}$ bonds in aromatic ring are also being equalized from magnesium to barium salts. It indicates that aromaticity of molecules increases along above series. However, aromaticity of acid is higher than those for salt molecules. This thesis is confirmed by almost all aromaticity indices [3]. They are visibly increase in the order $\mathrm{Mg}<\mathrm{Ca}<\mathrm{Sr}<\mathrm{Ba}$ m-nitrobenzoates. The increase of the values of dipole moment as well as of energy for alkaline earth m-nitrobenzoates was observed in comparison with m-nitrobenzoic acid. It indicates about perturbation of free acid aromatic system by studied cations.

The Mulliken atomic charges were also calculated (Table 1). The charges on O9 and O10 oxygen atoms (Fig. 1) in acid molecule are different $(-0.270$ and -0.468$)$, but this difference decreases for salts. In strontium ( -0.559 and -0.556$)$ and barium $(-0.556$ and -0.554$) \mathrm{m}$-nitrobenzoates the atomic charges of those oxygen atoms are almost equal. Total charges on $\mathrm{COO}^{-}$anion, nitro group and aromatic ring were calculated and presented in Table 1 . One can see a significant increase of negative values of $\mathrm{COO}^{-}$anion charge from magnesium m-nitrobenzoate to barium salt. Quite good correlations between 
Table 1

Calculated (B3LYP/LANL2DZ) values of dipole moment, energy, geometric aromaticity indices [3] and total charges for m-nitrobenzoates (MeNB)

\begin{tabular}{|c|c|c|c|c|c|}
\hline & NBA (acid) & $\mathrm{Mg} \mathrm{NB}$ & Ca NB & Sr NB & Ba NB \\
\hline \multicolumn{6}{|l|}{ Distance } \\
\hline $\mathrm{C} 1-\mathrm{C} 2$ & 1.407 & 1.408 & 1.407 & 1.407 & 1.406 \\
\hline C2-C3 & 1.402 & 1.401 & 1.402 & 1.402 & 1.402 \\
\hline C3-C4 & 1.406 & 1.407 & 1.407 & 1.407 & 1.407 \\
\hline C4-C5 & 1.405 & 1.405 & 1.405 & 1.405 & 1.404 \\
\hline C5-C6 & 1.405 & 1.405 & 1.406 & 1.407 & 1.407 \\
\hline C1-C6 & 1.412 & 1.413 & 1.412 & 1.412 & 1.411 \\
\hline $\mathrm{C} 1-\mathrm{C} 7$ & 1.488 & 1.478 & 1.489 & 1.493 & 1.498 \\
\hline C7-O9 & 1.243 & 1.314 & 1.309 & 1.307 & 1.305 \\
\hline $\mathrm{C} 7-\mathrm{O} 10$ & 1.385 & 1.316 & 1.310 & 1.309 & 1.306 \\
\hline \multicolumn{6}{|l|}{ Angle } \\
\hline $\mathrm{C} 1-\mathrm{C} 2-\mathrm{C} 3$ & 118.2 & 118.1 & 118.3 & 118.3 & 118.4 \\
\hline C2-C3-C4 & 122.5 & 122.4 & 122.4 & 122.4 & 122.4 \\
\hline C3-C4-C5 & 118.6 & 118.7 & 118.6 & 118.5 & 118.5 \\
\hline C4-C5-C6 & 120.2 & 120.2 & 120.2 & 120.2 & 120.2 \\
\hline $\mathrm{C} 5-\mathrm{C} 6-\mathrm{C} 1$ & 120.2 & 120.0 & 120.1 & 120.2 & 120.3 \\
\hline $\mathrm{C} 2-\mathrm{C} 1-\mathrm{C} 6$ & 120.4 & 120.7 & 120.4 & 120.3 & 120.2 \\
\hline \multicolumn{6}{|c|}{ Geometric aromaticity indices } \\
\hline HOMA $^{1}$ & 0.9126 & 0.9084 & 0.9095 & 0.9079 & 0.9129 \\
\hline$A_{\mathrm{J}}^{2}$ & 0.99896 & 0.9985 & 0.9990 & 0.9990 & 0.9991 \\
\hline $\mathrm{BAC}^{3}$ & 0.9627 & 0.9538 & 0.9627 & 0.9640 & 0.9654 \\
\hline$I_{6}{ }^{4}$ & 97.4533 & 96.9297 & 97.4814 & 97.4837 & 97.6424 \\
\hline$\Delta(\mathrm{C}-\mathrm{C})$ & 0.010 & 0.012 & 0.010 & 0.010 & 0.009 \\
\hline$\Delta(\mathrm{C}-\mathrm{C}-\mathrm{C})$ & 4.3 & 4.3 & 4.1 & 4.1 & 4.0 \\
\hline Dipole moment (debye) $)^{5}$ & 3.3656 & 6.4595 & 6.3876 & 6.4159 & 4.3848 \\
\hline Energy (hartree) ${ }^{6}$ & -625.2317 & -1250.2658 & -1285.9967 & -1279.8751 & -1274.6640 \\
\hline$E_{\mathrm{r}}^{7}(\mathrm{~kJ} / \mathrm{mol})$ & 0 & 51.72235 & 51.4598 & 64.32475 & 45.94625 \\
\hline \multicolumn{6}{|l|}{ Total Mulliken charges $(e)^{8}$} \\
\hline $\mathrm{COO}$ & -0.572 & -0.550 & -0.950 & -1.004 & -1.007 \\
\hline $\mathrm{NO}_{2}$ & -0.386 & -0.373 & -0.393 & -0.397 & -0.403 \\
\hline Aromatic ring & -0.584 & -0.573 & -0.613 & -0.605 & -0.559 \\
\hline
\end{tabular}

Notes: ${ }^{1}$ Abbreviation from harmonic oscillator model of aromaticity; ${ }^{2}$ Normalized function of variance of bond lengths; ${ }^{3}$ Bond alternation coefficient; ${ }^{4}$ Bird's index; ${ }^{5} 1 \mathrm{D}=3.33564 \times 10^{-30} \mathrm{C} \times \mathrm{m} ;{ }^{6} 1$ hartree $=2625.5 \mathrm{~kJ} / \mathrm{mol} ;{ }^{7} E_{\mathrm{r}}=$ $E(\mathrm{MeNB})-[E(\mathrm{Me})+2 E(\mathrm{NB})] ;^{8} e=1.6021892 \times 10^{-19} \mathrm{C}$.

total charges on $\mathrm{COO}^{-}$anion and $\mathrm{C} 1-\mathrm{C} 7, \mathrm{C} 7-\mathrm{O} 9$ and $\mathrm{C} 7-\mathrm{O} 10$ bond lengths were noted $\left(R^{2}=0.8821\right.$, 0.8921 and 0.8887 , respectively).

\subsection{Vibrational spectra}

The vibrational spectra of the synthesized m-nitrobenzoates were recorded and presented in Fig. 2. The influence of studied cations on vibrational structure of m-nitrobenzoates expresses in the shift of selected 


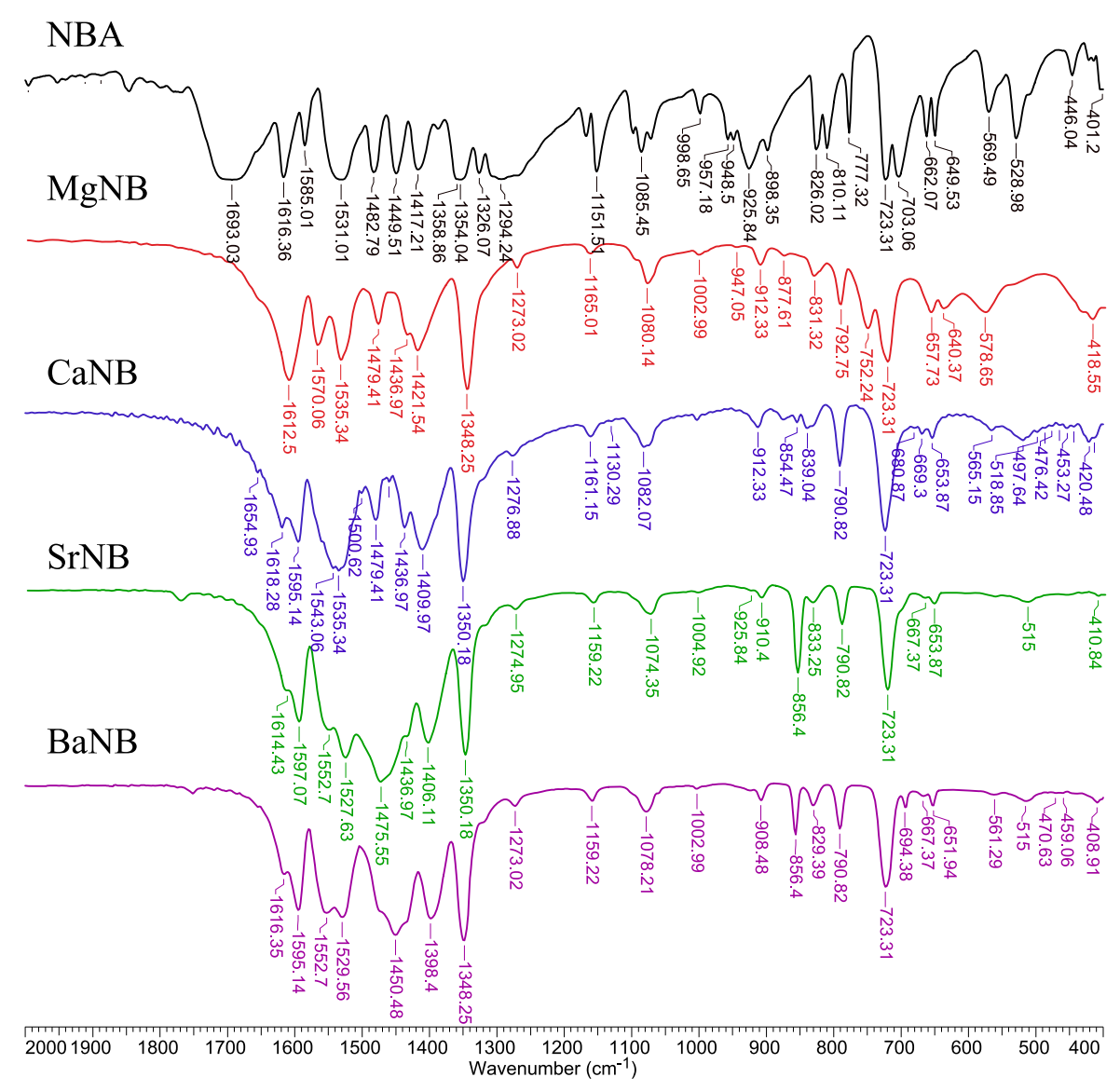

Fig. 2. FT-IR spectra of m-nitrobenzoic acid and alkaline earth metal m-nitrobenzoates.

bands along the metal series. The wavenumbers as well as intensity of the aromatic ring bands show decreasing tendency along the metal series for almost all bands. The wavenumbers of the symmetric as well as asymmetric stretching bands of carboxylic anion in IR spectra were decreased in the series $\mathrm{Mg} \rightarrow$ Ba. It was interested to note some correlations between experimentally obtained $\nu_{\text {as }}\left(\mathrm{COO}^{-}\right)$values and calculated $\mathrm{C} 1-\mathrm{C} 7, \mathrm{C} 7-\mathrm{O} 9$ and $\mathrm{C} 7-\mathrm{O} 10$ bond lengths $\left(R^{2}=0.7789,0.7857\right.$ and 0.7016 , respectively). Infrared spectroscopy is one of the methods applied to determine the mode of the carboxylate binding. The magnitude of separation between wavenumbers due to asymmetrical and symmetrical stretching vibrations of $\mathrm{COO}^{-}$group $\Delta \nu_{\text {as-s }}\left(\mathrm{COO}^{-}\right)$is used as this criterion. The values of them obtained for studied compounds decrease in the series $\mathrm{Mg}>\mathrm{Ca}>\mathrm{Sr}>\mathrm{Ba}$ m-nitrobenzoates. They are respectively as follows: $193,185,70$ and $52 \mathrm{~cm}^{-1}$. The value of $\Delta \nu_{\text {as-s }}\left(\mathrm{COO}^{-}\right)$for sodium m-nitrobenzoates equals 173 [7]. It may indicate monodentate coordination in the case of magnesium and calcium salts, because $\Delta \nu_{\text {as-s }}\left(\mathrm{COO}^{-}\right)$is higher for these salts than for sodium one. For strontium and barium m-nitrobenzoates the values of $\Delta \nu_{\text {as-s }}\left(\mathrm{COO}^{-}\right)$are much smaller than for sodium salt, it may suggest chelating mode $[5,9]$.

Some insignificant changes were also observed in wavenumbers of the bands responsible for nitro group in m-nitrobenzoates spectra. The values of $\Delta \nu_{\text {as-s }}\left(\mathrm{NO}_{2}\right)$ group are 172, 185, 187, 178, 182 (for acid, $\mathrm{Mg}, \mathrm{Ca}, \mathrm{Sr}$ and Ba salts, respectively). 


\section{Conclusions}

Study of alkali and alkaline-earth cations is of great importance, since they are present in large amounts in biological and nature fluids:

- The bond lengths and angles between $\mathrm{C}-\mathrm{C}-\mathrm{C}$ bonds in aromatic ring are being equalized from magnesium to barium salt. It indicates that aromaticity of molecules increases along above series. This thesis is confirmed by almost all aromaticity indices. Aromaticity visibly increases in the order $\mathrm{Mg}<\mathrm{Ca}<\mathrm{Sr}<\mathrm{Ba}$ m-nitrobenzoates, however free acid has higher aromaticity than salt molecules.

- The magnitudes of separation between wavenumbers due to asymmetrical and symmetrical stretching vibrations of $\mathrm{COO}^{-}$group indicate monodentate coordination in the case of magnesium and calcium salts, but chelating mode for strontium and barium m-nitrobenzoates.

\section{Acknowledgement}

Presented work was supported by Białystok Technical University (theme No. S/WBiIŚ/21/07).

\section{References}

[1] M.H. Borawska, P. Koczoń, J. Piekut, R. Świsłocka and W. Lewandowski, J. Mol. Struct. 919 (2009), 284-289.

[2] M.J. Frisch, G.W. Trucks, H.B. Schlegel, G.E. Scuseria, M.A. Robb, J.R. Cheeseman, V.G. Zakrzewski, J.A. Montgomery, R.E. Stratmann, J.C. Burant, S. Dapprich, J.M. Millam, A.D. Daniels, K.N. Kudin, M.C. Strain, O. Farkas, J. Tomasi, V. Barone, M. Cossi, R. Cammi, B. Mennucci, C. Pomelli, C. Adamo, S. Clifford, J. Ochterski, G.A. Petersson, P.Y. Ayala, Q. Cui, K. Morokuma, D.K. Malick, A.D. Rabuck, K. Raghavachari, J.B. Foresman, J. Cioslowski, J.V. Ortiz, B.B. Stefanov, G. Liu, A. Liashenko, P. Piskorz, I. Komaromi, R. Gomperts, R.L. Martin, D.J. Fox, T. Keith, M.A. Al-Laham, C.Y. Peng, A. Nanayakkara, C. Gonzalez, M. Challacombe, P.M.W. Gill, B.G. Johnson, W. Chen, M.W. Wong, J.L. Andres, M. Head-Gordon, E.S. Replogle and J.A. Pople, Gaussian 98 (Revision A.11.2), Gaussian, Inc., Pittsburgh, PA, 1998.

[3] T.M. Krygowski and M. Cyrański, Tetrahedron 52 (1996), 1713-1722.

[4] W. Lewandowski, M. Kalinowska and H. Lewandowska, J. Inorg. Biochem. 99 (2005), 1407-1423.

[5] K. Nakamoto, Infrared and Raman Spectra of Inorganic and Coordination Compounds, Wiley, New York, 1997.

[6] I. Soojhawon, P.D. Lokhande, K.M. Kodam and K.R. Gawai, Enzeme Microb. Technol. 37 (2005), 527-533.

[7] R. Świsłocka, E. Oleksiński, E. Regulska, M. Kalinowska and W. Lewandowski, J. Mol. Struct. 834-836 (2007), 380-388.

[8] R. Świsłocka, E. Regulska, M. Samsonowicz, T. Hrynaszkiewicz and W. Lewandowski, Spectrochim. Acta A 61 (2005), 2966-2973.

[9] V. Zelenák, Z. Vargová and K. Györyová, Spectrochim. Acta A 66 (2007), 262-272. 


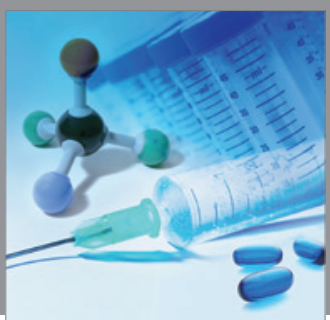

International Journal of

Medicinal Chemistry

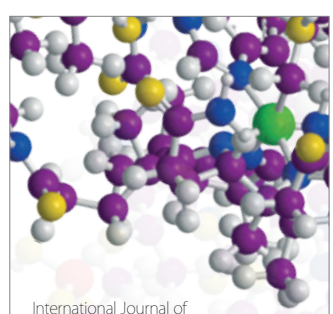

Carbohydrate Chemistry

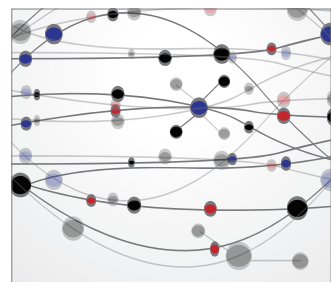

The Scientific World Journal
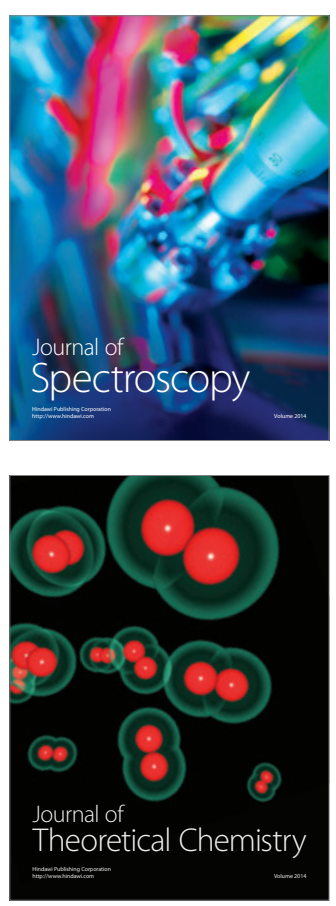
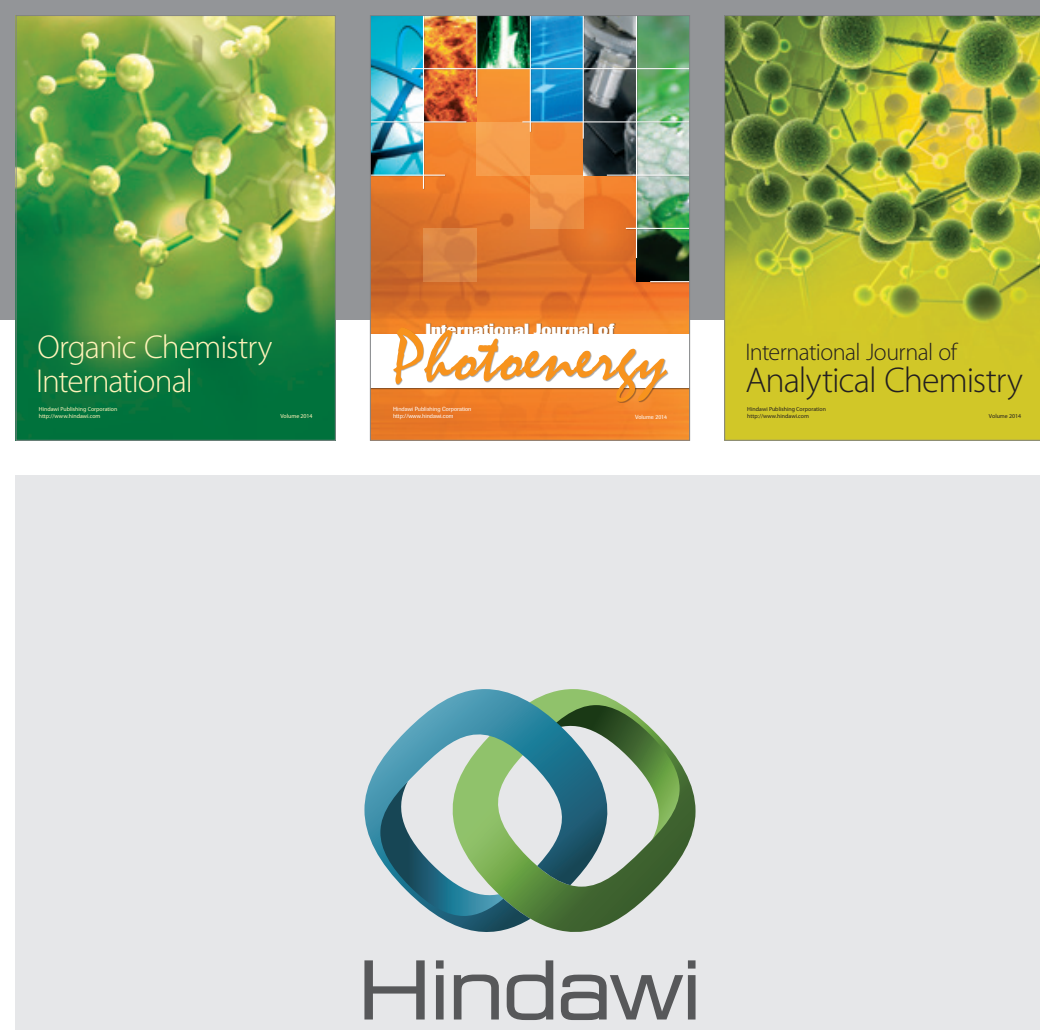

Submit your manuscripts at

http://www.hindawi.com
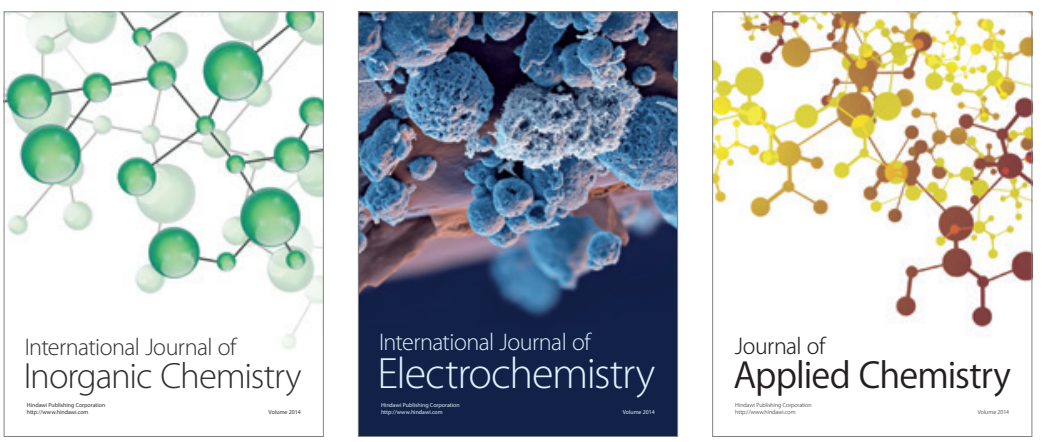

Journal of

Applied Chemistry
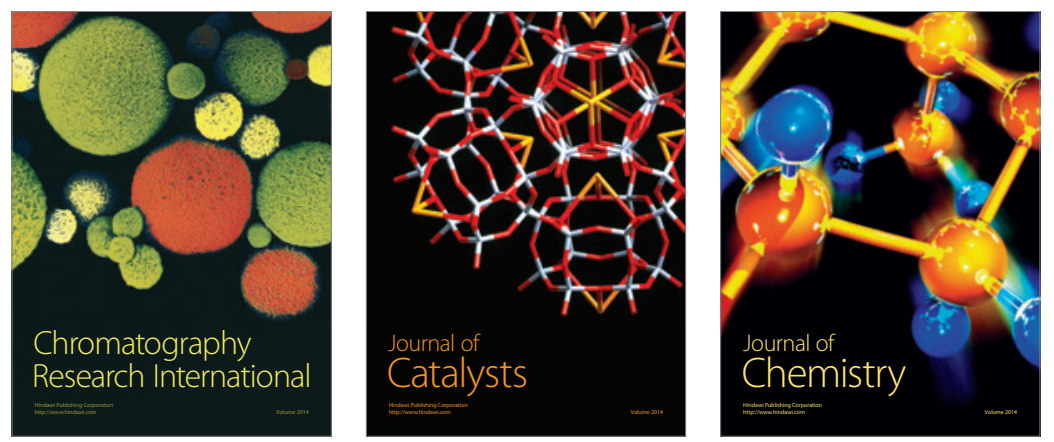
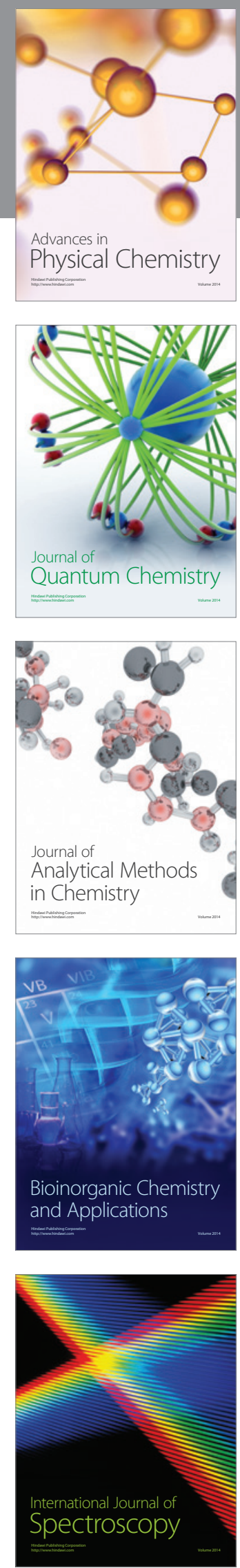